\title{
GPS Data Processing of Five Years of More Than 300 Permanent Station Archive with the Distributed Sessions Approach in Italian Peninsula
}

\section{Giuseppe Casula ${ }^{1, *}$}

1 Istituto Nazionale di Geofisica e Vulcanologia, Via Donato Creti 12 - I-40128 - Bologna - Italy; giuseppe.casula@ingv.it

* Giuseppe Casula; E-Mail: giuseppe.casula@ingv.it; Tel.: +39-051-4151415; Fax: +39-051-4151499.

Published: 22 June 2015

\begin{abstract}
A methodology to process more than 300 permanent Global Positioning System (GPS) station data located in the Italian Peninsula is presented, based on software Gamit/Globk 10.5 developed and maintained by MIT, Scripps Institution of Oceanography, and Harvard University with support from the National Science Foundation (http://www-gpsg.mit.edu/ simon/gtgk/), and using software tools based on the distributed sessions approach implemented in the package. The GPS data are comprised in the period January 2008 - December 2012, and belongs to several different permanent GPS network in Italy, like: the RING of the National Institute of Geophysics and Volcanology (INGV), ASI Italian spatial agency, EUREF - European Reference Network, IGS International GNSS Service for geodynamics, ITALPOS of Leica Geosystems Italy and other institution networks maintained by public and private administration and universities. The data collected daily by different sensors and archived in RINEX compressed Hatanaka format are gathered, divided in several clusters, and routinely processed using Gamit data processor, based on least square method.

We combined our solutions with SOPAC (http://garner.ucsd.edu) ones to obtain stable and high quality solutions ( $h$ files) containing coordinates, velocities and covariance of more than 300 GPS sites. A Global Kalman filter based package (Globk) is used to compute position time series and velocities registered in the ITRF2008 reference frame. Indications about the tectonics of Mediterranean regions can be inferred by the resulting high density intra-plate velocity field.
\end{abstract}

Keywords: GPS; big data handling; distributed sessions, tectonics 


\section{Introduction}

Nowadays several technological improvements have been implemented in the hardware and software applied to GPS technology. Modern receiver can be easily operated by remote sites and directly connected to the internet. In particular, practically all the standards modern instruments for permanent GPS stations available for the user in the commerce are provided with ftp and web server and can be connected directly to the internet with the aid of mobile phone technologies, and in such a way can be remotely operated.

Facilities for the real time monitoring and positioning with the GPS technique are freely available to the user. Modern receiver can be operated by means of user friendly object-oriented utilities implemented in the GUIs (Graphic User Interface). Static and kinematic positioning application are widely used for the positioning of aircraft or cars on roads. In Italy more than 600 permanent GPS stations are available quite uniformly distributed on the territory for different purposes.

Several continuous GPS (CGPS) station network are operated by different public and private companies in order to provide to the user services like, kinematic ambiguity corrections, cars and aircraft real time positioning or the monitoring of environmental phenomena like crustal deformation, geodynamics phenomena like, subsidence or uplift of appenninic or alps chains due to the post glacial rebound, and active volcanoes real time monitoring.

High rate real time kinematic applications are useful for the coseismic crustal movement computation and consequent characterization of the seismogenetic structures.

In the following of this work we describe the methodology applied for the computation of CGPS data solutions used for the estimation of stable high quality velocity field of more than 300 permanent station distributed quite uniformly in the Italian Peninsula in the time span January 2008 - December 2012. Starting from the description of the data processing following a distributed session multi-step procedures to reach the task of computing dense velocity field and strain of the total network.

\section{Experimental Section}

\subsection{Experimental data}

We build an archive of daily RINEX (Receiver Independent Exchange) format data compressed with the Hatanaka compressor (Hatanaka, 2008) and finally compressed by means of our implementation of software tools written in Unix $c$-shell and $b$-shell languages calling fortran and $c$ subroutines and mains. By these facilities we are able to build and maintain our GPS data archive.

We download from the internet GPS data belonging to different network maintained by different public and private companies. We start from the RING (Rete Integrata Nazionale GPS) (http://bancadati2.gm.ingv.it) maintained by the National Center of Earthquakes (CNT) of the Istituto Nazionale di Geofisica e Vulcanologia (INGV) (Avallone et al., 2010). This network that is maintained 
by CNT of INGV personnel make available many CGPS stations data also for the Leica Geosystems Italy Italpos (http://it.smartnet-eu.com/) permanent GPS network.

The RING network has been implemented for the routinely computation of the strain of the Italian Peninsula and mainly for seismological and volcanic studies. The quality of the RING network data is greater than other network data. In particular the monuments are build using high quality scientific standard.

Italpos is a network of about 150 CGPS sites maintained by Leica Geosystems Italy S.p.A. for commercial purposes to transmit the kinematic corrections and ambiguities to interested user who wants to kinematic and rapid-static positioning points in the territory with the aid of single receiver. A convention between INGV and Leica was stated to involve several sites belonging to RING network in ItalPos in such a way to involve INGV personnel in the maintainage of ItalPos network sites too.

The Italian Space Agency (ASI) maintains a permanent CGPS network in the Italian territory, and some sites in Greek, the data are available via ftp (file transfer protocol) at the site of ASI (ftp://geodaf.mt.asi.it), solutions are computed mainly by Bernese (http://www.bernese.unibe.ch/), and Gipsy-Oasis (https://gipsy-oasis.jpl.nasa.gov/) software and made available to the scientific community and all user freely accessing the ASI ftp server.

ASI solutions and stations are involved in the EUREF EPN (European Reference Network) network project (Bruyninx, 2004, Bruyninx et al., 2012), an European Network of CGPS stations distributed mainly in the territory of Eurasia plate, extending from Asiatic and Russian sites to Greenland sites in latitude and from North African sites to polar stations located in Island, Norway and so on, in longitude. Network solution and data are made available to the scientific community by free ftp access at the site (http://www.epncb.oma.be/), together with meta data describing the characteristic of instrumentation used in the sites and monuments. Solution are available for more than 400 permanent station in IGB08, ITRF2008 and other reference frames. Intra plate velocities are made available (ETRF2008), successful comparison are possible between our solution and EUREF solutions for coordinates and velocities. Contribution are given by the EUREF project to the definition of reference frames, Earth Orientation Parameter (EOP), and precise Orbits to International GNSS (Global Navigation Satellite Systems) service for Geodynamics (IGS).

Together with the previously described network data we involved in our solutions also the CGPS sites of different Regions and Provinces Italian networks. In particular we gathered the data of the best quality permanent sites of the following regional institutions in which the Italian territory is administratively divided: Emilia Romagna, Toscana, Liguria, Piemonte, Lombardia, Veneto, Friuli Venezia Giulia, Calabria, Puglia, and Provincia Autonoma of Trento and Bolzano available of (http://bancadati2.gm.ingv.it). Like for the ItalPos network sites the quality of data was the discriminant for a choice if to combine or not these data solutions with the ones of scientific institutions like, INGV, EUREF and ASI. 


\subsection{GPS data processing}

We used Gamit (GPS at MIT) data processor developed at the Harvard Smithsonian Center of Astrophysics, Massachusetts Institute of Technology, and the Scripps Institution of Oceanography, University of California, San Diego (Herring et al. 2010a). Gamit software is composed of different programs for GPS data processing that can be applied sequentially using Unix $c$-shell utilities. It is mainly used to compute loose constrained daily solutions of all the clusters by estimating also coordinates, variance-covariance matrices, ambiguities, atmospheric delays, and sometimes orbital parameters.

For the sake of convenience we divided the data to be processed in 20 clusters of about 15 CGPS sites. 8 EUREF fiducial sites data are added in all the clusters solutions: CAGL, GENO, MATE, NOT1, PADO, WTZR, GRAZ, POTS in order to constrain the solutions in the best way. In order to improve the stability of the solutions and to facilitate the combination process we adopted the same sestbl. setup file to model all the bias. Moreover, the chosen setup is actually compatible with SOPAC (http://garner.ucsd.edu) regional clustering.

Gamit solutions were automatically iterated by applying a weighted least-squares algorithm at least twice in order to reduce the residuals of the estimated coordinates with respect to the a-priori from centimeters to millimeters. The software is able to repair or remove cycle slips with the aid of AUTCLN program acting on double or triple differences observables.

Ambiguities were resolved in high percentages (more than 90\%) using the Melbourne-Webbena wide-lane linear combination of phase and codes (Dubbini et al., 2010).

We used systematically for all the solutions the precise IGS geocentric orbits. As listed in the sestbl. (session processing table file) to account for the dynamic models used in the standard processing we used the following models known in literature: the default gravitational field of IERS-1992 (McCarthy, 1996), the model for non-gravitational accelerations of satellites given by (Colombo, 1986; Beutler et al., 1994).

To take into account the azimuthal asymmetry effects, an estimations of both zenithal delays and of the atmospheric gradients is necessary by means of the application of a linear piecewise function covering the all period of the observations (Dubbini et al., 2010). The Saastamoinen [1972] model was used to estimate the dry and wet parts of the atmospheric delays, moreover to model the a-priori zenith delay correction we adopted the global pressure and temperatures (GPT) 50 model implemented and discussed in (Boehm et al. 2006a,b).

By applying this model values of pressure and temperatures are generated as function of both site position and time, simply by fitting meteorological data with the aid of spherical harmonics. Moreover, for every site the values of zenith delay corrections are extrapolated from a a-priori global grid file computed with the aid of the Vienna Mapping functions (Boehm et al., 2006b). 
Even if the Iono-free observable is used during the processing i.e. a phase linear combination which is inherently free of the $90 \%$ of the ionospheric effect, it was necessary to reduce the contribution of the ionosphere by modeling and stochastically adjustment of this bias.

To account for the main components of solid earth tides (diurnal, semi-diurnal, ter-diurnal, weekly, monthly, semi-annual and annual) we applied the global model implemented by (Petit, and Luzum, 2004). Pole-tide corrections were applied according to the IERS standards [Dong et al., 2002; Herring et al., 2006]. The tidal effect of oceanic loading was modeled by means of the FES2004 tidal model implemented at Centre National d'Etudes Spatiales (Lyard et al., 2006).

Different type of receivers with different antenna are mixed in our solutions, in such a way that was necessary to introduce in the processing the upgraded version of absolute antenna phase center correction models given by IGS and made available on garner ftp site (ftp://garner.ucsd.edu).

\subsection{Solution combination and compensation}

Globk is a kalman filter useful for combination, stabilization, coordinates compensation, position time series computation, and reference frame definition with Euler pole estimates of data processed with different GPS software processors like Gamit. Globk has been developed and maintained by MIT, Scripps Institution of Oceanography, and Harvard University, and partially supported from the National Science Foundation (http://www-gpsg.mit.edu/ simon/gtgk/), it can manage also quasiobservation solution of other standards like Bernese and Gipsy (Herring et al., 2010b).

To compute position time series of CGPS stations together with station velocities we adopted a multi-step procedure (see Figure 1), starting from the so called quasi-observation i.e. cluster solution computed during Gamit processing (h-files) containing loose-constrain weighted least squares estimates of site coordinates, variance-covariance, atmospheric models, orbits and so on (Dong et al. 1998; Serpelloni et al. 2006; Dubbini et al. 2010).

The first step is to form observations from quasi-ones by combining our solutions with the regional cluster solutions of SOPAC, this operation is done using the Globk program by down-weighting with appropriate weights the $h$-files taking into account the noise of the solutions.

The robust combination process as stated by Dong et al. 1998 is obtained when precise IGS orbits are used during the processing, and at least two or better three fiducial sites are common to all the solutions (h-files). After the combination process, daily combined observation of all the 20 clusters used are obtained. In fact it is easy to demonstrate that the result of a simultaneous solution of a whole network is equivalent to the result obtained by splitting this network in many clusters that can be solved separately using little computers clusters, and finally combined to obtain complete network solutions (Dong et al., 1998; Castagnetti et al. 2009).

After robust combination session a first compensation of the network must be done to compute siteby-site position time series for the NEU (North East Up) components in a known reference frame. It is possible to register the network sites in ITRF2008 or IGB08 reference frames (Altamimi et al., 2008), 
by loose constraining known positions and velocities of fiducial sites made available by EUREF or SOPAC facilities in ITRF2008 or IGB08 during Globk solution of the network.

Interactive editing with Herring Matlab Tools (Herring, 2003), and processing with Williams Create and Analyze Time Series (CATS) (Williams, 2008) package based on maximum likelihood method are necessary to estimate site-by-site noises, to subtract annual and semi-annual components, and to estimate both offsets and outliers. It is also possible to apply other analysis center estimates of site offsets due to instrumental changes in a single run of the Global Kalman Filter (Globk).

Robust fit (ENFIT) of the network sites position time series are used to compute site-by-site Markov condition by which the correct amount of time dependent noise is added to the sites error ellipses during the final run of the Globk Kalman filter.

To remove the almost rigid rotation of Eurasian plate it is possible to apply the cvframe utility to Globk solutions, which uses the Altamimi's definition of pole published in ITRF2008 (Altamimi et al., 2008). The other way is to call the subroutine plate implemented in the global origin tool (Glorg) of Globk which make an estimate of the rotation pole of the Eurasian plate by loose constraining several fiducial sites whose position and velocities are known.

Finally, the $\chi^{2}$ parameter of the single daily network solution is used to weight the final network solution and to estimate more realistic error ellipses of the sites considered (Herring et al. 2010b).

\section{Results and Discussion}

As stated above combined daily solutions of an Italian regional cluster of more than 300 permanent GPS sites have been realized starting from our solutions $h$-files and using regional cluster solutions taken from garner facility.

Daily combined solutions were stabilized using EUREF a-priori coordinated and velocities in ITRF2008 to loose constrain our combined whole network daily h-files (Fig. 2,3). The almost rigid rotation has been removed by means of Globk global origin ( $\mathrm{glorg}$ ) tool in order to compute intra-plate residual horizontal velocities for all the sites.

More than 50 sites shows residual horizontal velocities little than $1 \mathrm{~mm} / \mathrm{y}$ proving the good quality of the solutions and that the application of the Altamimi's ITRF2008 definition of Eurasian absolute rotation pole is correctly implemented (see Fig. 4).

By this procedure, several hundreds of permanent GPS station data can be processed and combined. Horizontal and vertical velocity contains the effects of slow moving environmental phenomena like micro plate motion, subsidence, post-glacial rebound, and sometimes volcanic areas movements.

In particular, looking at the whole network solution, evidence of Nubia plate North-East motion are visible in the station located in southern part of Mediterranean sea, like: LAMP, MALT and PZIN, but also looking at the residual velocities of the Southern East part of the Sicily (see Fig. 4). 
The sites belonging to Sardinia and Corse block shows very little no significant residual horizontal velocities proving that this regions are very stable and follows the motion of Eurasian plate (Serpelloni et al., 2005, 2007; Devoti et al. 2011).

Figure 1. Scheme of the GPS multi-step data processing based on the distributed sessions approach.

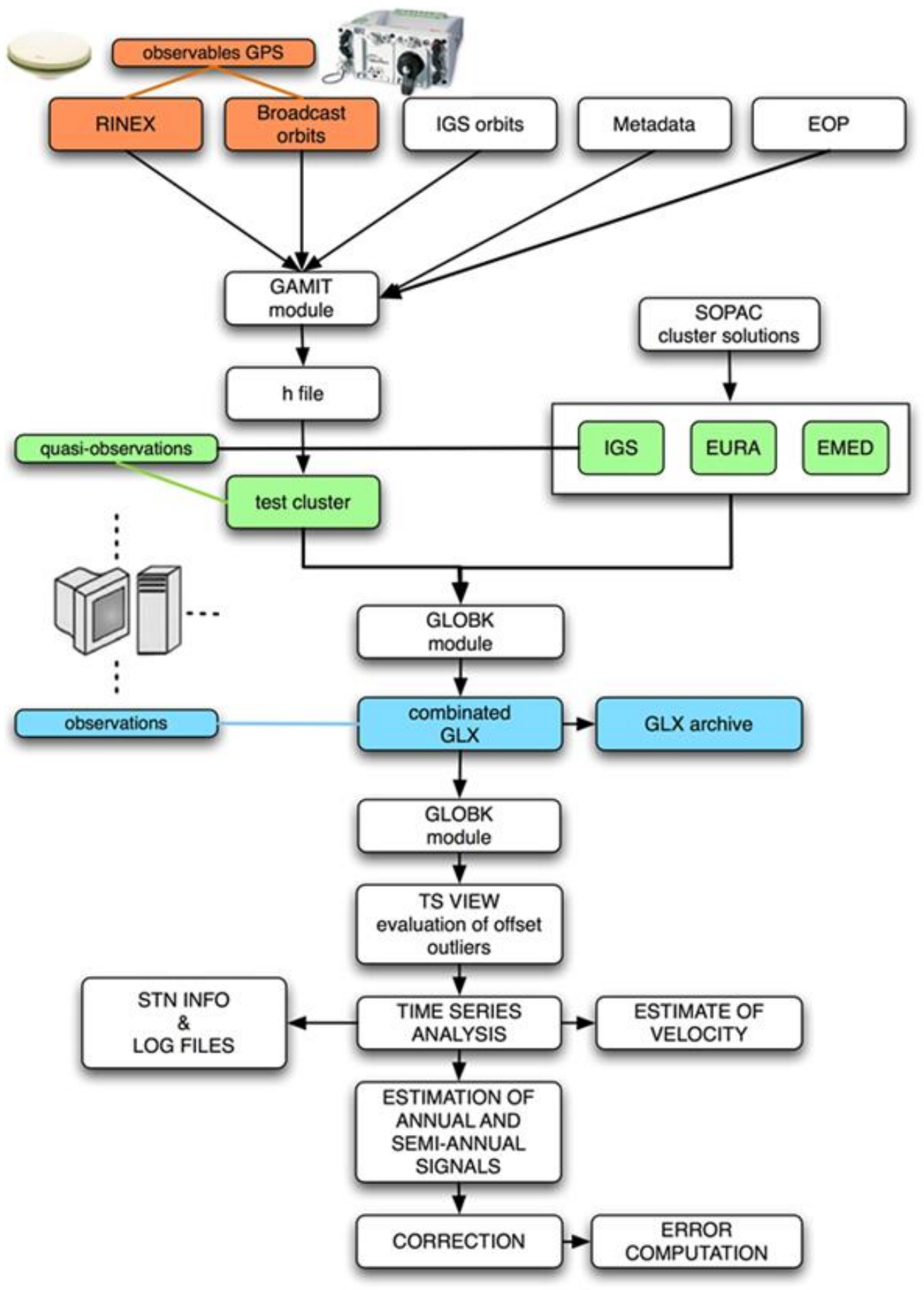


Figure 2. CGPS permanent sites of the EUREF EPN network used in this work. The majority of these sites shows residuals horizontal velocities little than $1 \mathrm{~mm} / \mathrm{y}$. The Figure has been produced with sh_plot_lfile Unix c-shell utility of Gamit package.

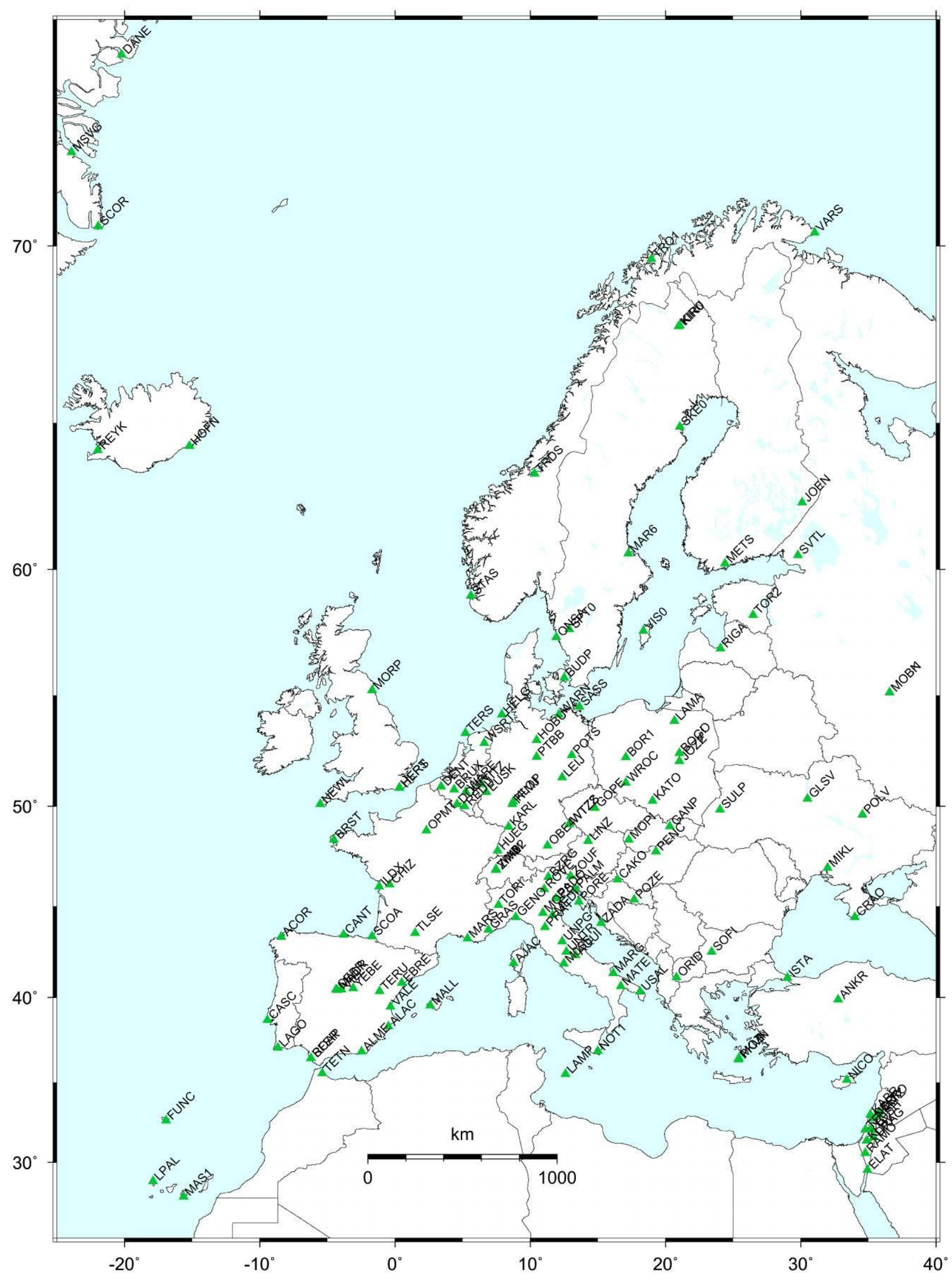


In the continental area of the Italian Peninsula some interesting large scale effects can be appreciated looking at the network dense residual velocity solution. In particular, at a scale of $50 \mathrm{~km}$ the Messina Straits sites shows 5-6 mm/y residual velocities and an extensional movement along the North-East South-West direction (Fig. 4).

Southern Italian Apennines sites, where the RING network is more dense, and the quality of sites is better, we can appreciate residual horizontal velocities of about $5 \mathrm{~mm} / \mathrm{y}$ in the North-East direction indicating at large scale the delineation and the counterclockwise rotation of the Apulian plate (Serpelloni et al. 2005, 2007).

Moreover, in general along the appenninic chain the residuals velocities of our solution shows an extensional regime coming from West to East. The three station of: LICO, IPRO and RITE shows an anomalous trend of expansion due to the Campi-Flegrei caldera movement of the period 2008-2012 (De Martino et al., 2013).

The residual horizontal velocities of sites belonging to the Adriatic plate shows a relative motion of about 3-4 mm/yr in the North-East direction as indicated by other authors, and are useful to delineate this tectonic structure (D’Agostino et al., 2008; Baldi et al., 2015).

The Padania plate vertical velocities are affected by a subsidence negative trend scattering in the range $-1-4 \mathrm{~mm} / \mathrm{y}$ due essentially to the extraction of water for industrial and civil usage done in this area (see Fig. 5) (Baldi et al. 2009; 2015). The same phenomenon is noticeable in some area of the Sicily were water are extracted from wells for civil usage. Concerning the horizontal velocities of Padania plate, North-East movements residuals of about 3-4 mm/y can be appreciated in the Figure 4, showing a compressional trend in the area struck by the Emilian May-June 2012 earthquakes.

In the areas of the appennines and alps chains, vertical GPS velocities are positive showing a little 1-2 mm/y post glacial rebound signal (Fig. 5) (Baldi et al. 2015).

In the areas of North West sites in the regions of Piemonte, Liguria and Lombardia residual horizontal velocities shows relative motions very little and no significant. Conversely, in the Central appenninic area near Toscana, Lazio and Abruzzi regions we can appreciate that moving for West to East along the appenninic chain, velocities direction and intensities varies between West wise residual motion to North-East wise residual movements testifying an extensional tectonic regime along this mountain chains.

Residual velocities of our solution are characterized by error ellipses at $95 \%$ of confidence, scattering in the range $0.2-0.3 \mathrm{~mm} / \mathrm{y}$ for horizontal axis and less than $1 \mathrm{~mm} / \mathrm{y}$ in vertical, testifying both the high quality of data and solutions. 
Figure 3. ITRF2008 velocity solutions of the whole network solution presented in this work, figures are produced automatically with the aid of the Gamit/Globk sh_plotvel unix shell based on GMT package. North-East general motion of about $2.5 \mathrm{~cm} / \mathrm{y}$ of the Eurasian plate is clearly evident.

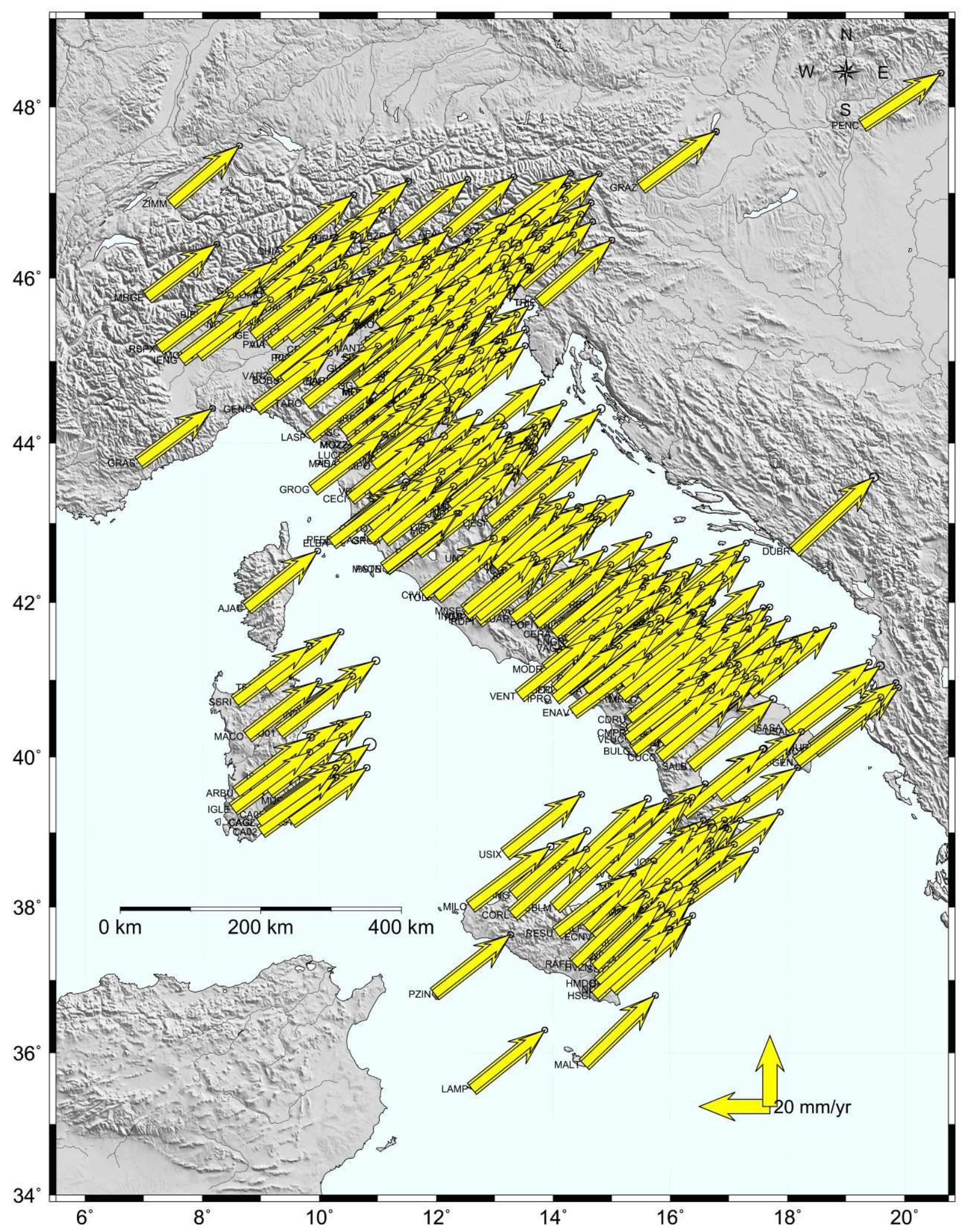


Figure 4. Residual Horizontal intra-plate velocities of 300 hundreds CGPS solution discussed in this work. After subtracting the rigid rotation of Eurasian plate indicated in Altamimi's definition.

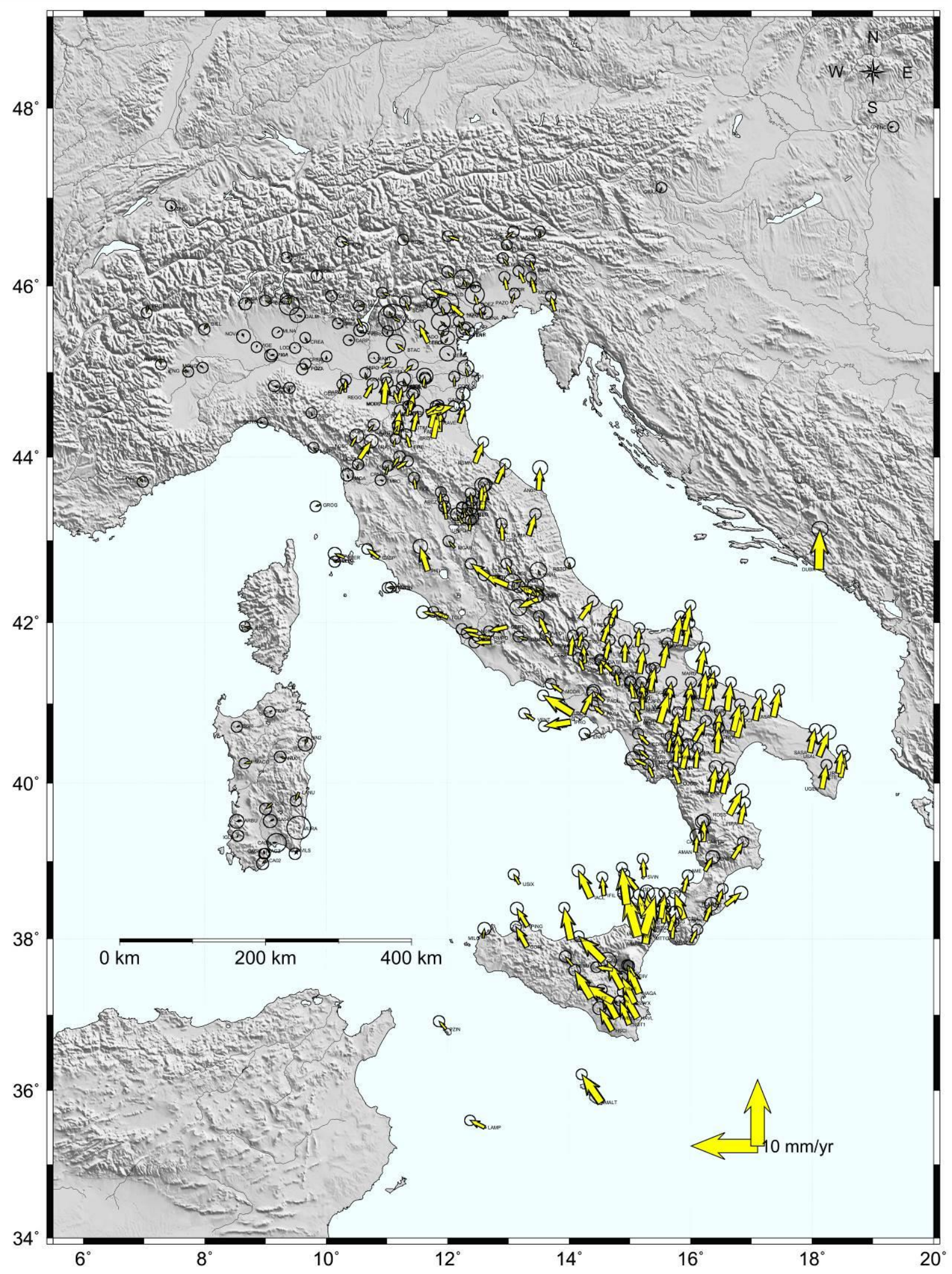


Figure 5. Vertical GPS velocities computed in this work. Error ellipses have been omitted for simplicity, in red negative and in blue positive velocities.

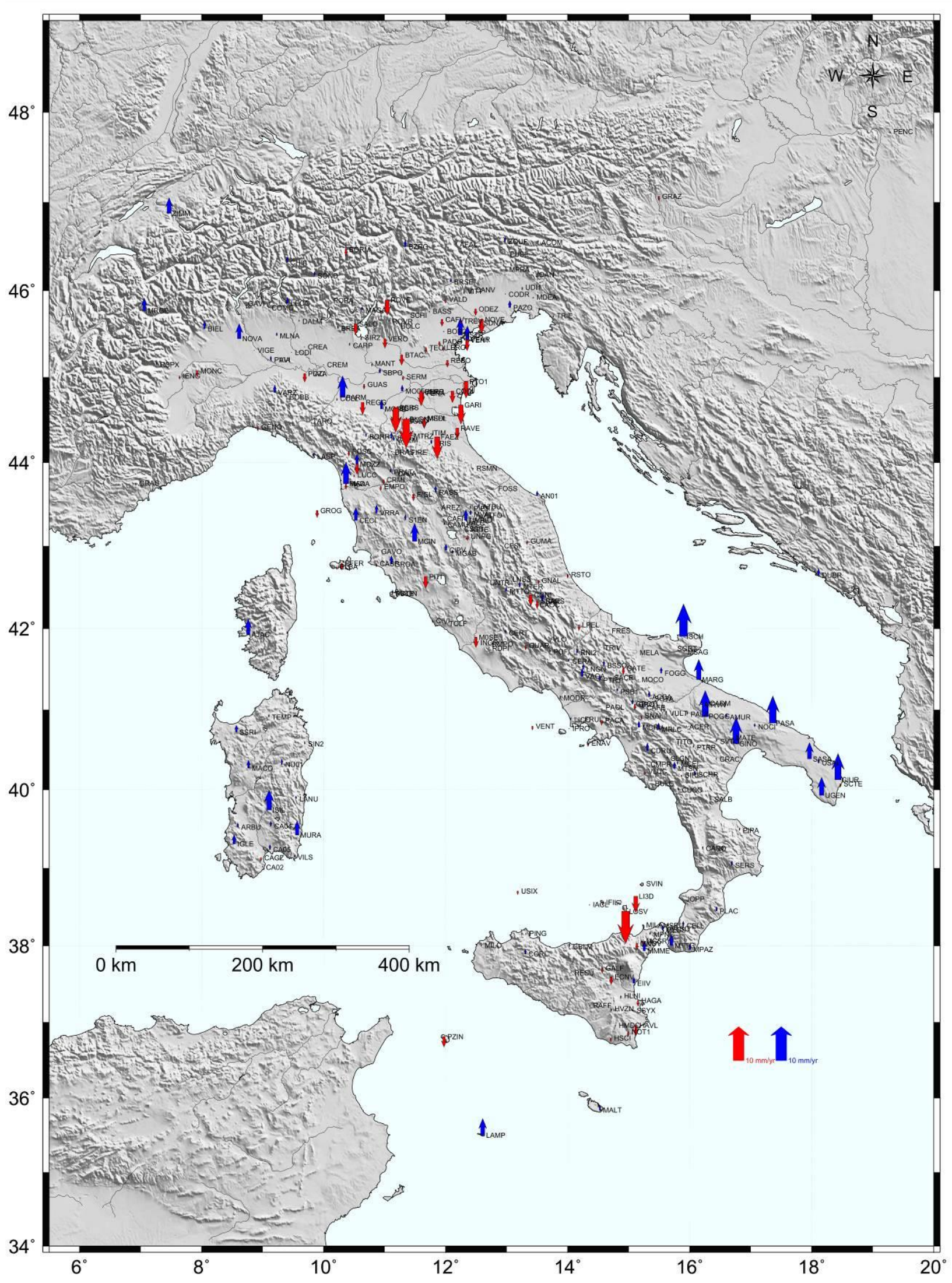




\section{Conclusions}

A methodology based on the distributes sessions approach and on the GPS data analysis software package Gamit/Globk written in FORTRAN language, Unix c-shell and $c$, and running on all Unix environments is presented in this work and seems to be effective for handling several hundred of GPS sites networks.

Data are gathered from different GPS network cited above and after archive population are routinely processed by dividing the whole network in little clusters that can be processed by little architecture machines clusters (Personal Computers Clusters).

Combined stable good quality solutions are obtained after robust combination of our solutions and GARNER facility ones to obtain daily solutions ( $h$-files) of the whole network of about 300 stations.

Solutions can be automatically format converted in SINEX (Solution independent exchange format) and made available to the scientific community.

Velocities and coordinates are stabilized in the ITRF2008 reference frame and residual intra-plate velocities are computed showing interesting large scale indications on the tectonics of the Mediterranean area.

Data are represented using Unix c-shell based on the Generic Mapping Tools (Wessel, \& Smith, 1998) graphic package. For the Digital Elevation Model (DEM) of the Italian peninsula we used GEBCO 30 arc-second grid ( (http://www.gebco.net/data_and_products/gridded_bathymetry_data/) .

\section{Acknowledgments}

This research has been partially founded by the Italian Presidenza del Consiglio dei Ministri Dipartimento della Protezione Civile (DPC) within the INGV-DPC 2007-2009 agreement (project S1). We are strongly indebted with the INGV-CNT Grottaminarda and Roma researchers and technicians for the management of the data archive of all the permanent networks in Italy and for the maintenance of the RING network continuous GPS stations. We want to thank all personnel working on regional and global GPS permanent networks and database maintenance (ASI, EUREF, ITALPOS, MIT, SOPAC and many other institutions, universities and agencies). Figures 2, 3, 4 and 5 have been produced by means of Generic Mapping Tools software (Wessel and Smith, 1998). DEM used in the figures have been downloaded from GEBCO web site.

\section{Author Contributions}

All parts of this work have been realized by Giuseppe Casula

\section{Conflicts of Interest}

State any potential conflicts of interest here or "The author declare no conflict of interest". 


\section{References and Notes}

1. Altamimi, Z., Métivier, L., Collilieux, X. ITRF2008 plate motion model. J. Geophys. Res. 2012, 117, B07402, doi:10.1029/2011JB008930.

2. Avallone, A., Selvaggi,G., D'Anastasio, E., D'Agostino, N., Pietrantonio,G., Riguzzi, F., Serpelloni, E., Anzidei, M., Casula, G., Cecere, G., D'Ambrosio, C., De Martino, P., Devoti, R., Falco, L., Mattia, M., Rossi, M., Obrizzo, F., Tammaro, U., Zarrilli, L. The RING network: improvement of a GPS velocity field in the central Mediterranean. Annals of Geophysics 2010, 53, 2, 39-54.

3. Baldi, P., Casula, G., Cenni, N., Loddo, F., Pesci, A. GPS-based monitoring of land subsidence in the Po Plain (Northern Italy). Earth Planet. Sci. Lett. 2009, 288, 204-212. doi:10.1016/j.eps1.2009.09.023.

4. Baldi, P., Devoti, R., Riguzzi, F., Pietrantonio, G. Satellite positioning and geophysics studies in Italy. Rend. Fis. Acc. Lincei 2015, DOI 10.1007/s12210-015-0385-6.

5. Beutler, G., Brockmann E., Gurtner W., Hugentobler U., Mervart L., Rothacher M. Extended orbit modeling techniques at the CODE Processing Center of the International GPS Service for Geodynamics (IGS): Theory and initial results. Manuscr. Geod. 1994, 19, 367-386.

6. Boehm, J., Niell, A., Tregoning, P., Schuh H. Global Mapping Function (GMF): A new empirical mapping function based on numerical weather model data. Geophys. Res. Lett. 2006a, 33, L07304, doi:10.1029/2005GL025546.

7. Boehm, J., Werl, B., Schuh, H. Troposphere mapping functions for GPS and very long baseline interferometry from European Centre for Medium-Range Weather Forecasts operational analysis data. J. Geophys. Res. 2006b, 111, B02406, doi:10.1029/2005JB003629.

8. Bruyninx C. The EUREF Permanent Network: a multi-disciplinary network serving surveyors as well as scientists. GeoInformatics 2004, 7, 32-35.

9. Bruyninx C., Habrich H., Sõhne W., Kenyeres A., Stangl G., Võlksen C. Enhancement of the EUREF Permanent Network Services and Products. "Geodesy for Planet Earth", IAG Symposia Series 2012, 136, 27-35, DOI 10.1007/978-3-642-20338-1_4.

10. Castagnetti, C., Casula, G., Dubbini, M., Capra, C. Adjustment and transformation strategies of ItalPoS Permanent GNSS Network. Annals of Geophysics 2009, VOL. 52, N. 2, April 2009.

11. Colombo, O. L.; Ephemeris errors of GPS satellites, Bull. Geodes. 1986, 60, 64-84.

12. D'Agostino, N., Avallone, A., Cheloni, D., D'Anastasio, E., Mantenuto, S., Selvaggi G. Active tectonics of the Adriatic region from GPS and earthquake slip vectors. J. Geophys. Res. 2008, 113, B12413, doi:10.1029/2008JB005860.

13. De Martino, P., Tammaro, U., Obrizzo, F. GPS time series at Campi Flegrei caldera (20002013). Annals of Geophysics 2014, 57, S0213. http://dx.doi.org/10.4401/ag-6431.

14. Devoti, R., Esposito, A., Pietrantonio, G., Pisani, A.R., Riguzzi, F. Evidence of large scale deformation patterns from GPS data in the Italian subduction boundary. Earth Planet. Sci. Lett. 2011, 311, 230-241. http://dx.doi.org/10.1016/j.epsl.2011.09.034.

15. Dong, D. N., Herring, T. A., King R. W. Estimating regional deformation from a combination of space and terrestrial geodetic data. J. Geod. 1998, 72, 200-214.

16. Dubbini, M., Cianfarra, P., Casula, G., Capra, A., Salvini F. Active tectonics in northern Victoria Land (Antarctica) inferred from the integration of GPS data and geologic setting. $J$. Geophys. Res. 2010, 115, B12421, doi:10.1029/2009JB007123.

17. Hatanaka, Y. A Compression Format and Tools for GNSS Observation Data. Bulletin of the Geographical Survey Institute 2008, 55, 21-30.

18. Herring T.A. MATLAB Tools for viewing GPS velocities and time series. GPS Solut. 2003, 7(3), 194-199.

19. Herring, T.A., R.W. King, R.W., McClusky, S.C. GPS Analysis at MIT, GAMIT Reference Manual, Release 10.5. (Department of Earth, Atmospheric, and Planetary Sciences 
Massachusetts Institute of Technology, Cambridge MA 2010a, available on line at http://wwwgpsg.mit.edu/ simon/gtgk/GAMIT_Ref.pdf accessed 12 May 2015).

20. Herring, T.A., R.W. King, R.W., McClusky, S.C. Global Kalman filter VLBI and GPS analysis program, GLOBK Reference Manual, Release 10.5. Department of Earth, Atmospheric, and Planetary Sciences Massachusetts Institute of Technology, Cambridge MA 2010b, available on line at (http://chandler.mit.edu/ simon/gtgk/GLOBK_Ref.pdf, accessed 12 May 2015).

21. Petit G., Luzum B. IERS Conventions (2010). (IERS Technical Note ; 36) Frankfurt am Main: Verlag des Bundesamts für Kartographie und Geodäsie, 2010, 179, ISBN 3-89888-989-6.

22. Serpelloni, E., Anzidei, M., Baldi, P., Casula, G., Galvani, A. Crustal velocity and strain-rate fields in Italy and surrounding regions: new results from the analysis of permanent and nonpermanent GPS networks. Geophys. J. Int. 2005, 161, 861-880. doi:10.1111/j.1365246X.2005.02618.x.

23. Serpelloni, E., Casula, G., Galvani, A., Anzidei M., and Baldi, P. Data analysis of permanent GPS networks in Italy and surrounding regions: application of a distributed processing approach. Annals of Geophysics 2006, 49 (4-5), 1073-1104.

24. Serpelloni, E., Vannucci, G., Pondrelli, S., Argnani, A., Casula, G., Anzidei, M., Baldi, P., Gasperini, P. Kinematics of the Western Africa-Eurasia plate boundary from focal mechanisms and GPS data. Geophys. J. Int. 2007, 169, 1180-1200. doi:10.1111/j.1365-246X.2007.03367.x.

25. Shen, Z.K., Jackson, D.D., Ge, B.X. Crustal deformation across and beyond the Los Angeles basin from geodetic measurements. J. Geophys. Res. 1996, 101, 27,957-27,980.

26. Wessel, P., and Smith, W. H. F. New, improved version of Generic Mapping Tools released. Eos Trans. AGU 1998, 79(47), 579 - 583.

27. Williams S.D.P. CATS: GPS coordinates time series analysis software. GPS Solut. 2008, 12(2), $147-153$.

(C) 2015 by the authors; licensee MDPI, Basel, Switzerland. This article is an open access article distributed under the terms and conditions of the Creative Commons Attribution license (http://creativecommons.org/licenses/by/4.0/). 